\begin{tabular}{c} 
International Journal of Engineering \& Technology, 7 (3.6) (2018) 364-367 \\
International Journal of Engineering \& Technology \\
SPC \\
Website: www.sciencepubco.com/index.php/IJET \\
Research paper \\
\hline
\end{tabular}

\title{
Root Cause Detection for Excess Control Rod Vibration in Fuel Injection Pump Using Shainin Methodology
}

\author{
Shivdarshan Sherugar ${ }^{*}$, K. Jaychandran ${ }^{2}$ \\ ${ }^{I}$ Dept. Of Mechanical, Acharya Institute Of Technology, Bangalore, India. \\ ${ }^{2}$ Manufacturing Process, Bosch Ltd, Bangalore, India. \\ E-Mail:Jen1976@Gmail.Com \\ *Corresponding Author E-Mail:Shivdarshanb@Acharya.Ac.In
}

\begin{abstract}
Fuel Injection Pump (FIP) is one of the important component of any engine and any issue related to FIP will directly affect the engine. One such issue is excess vibration at full load in multi-cylinder fuel injection pump. Many problem-solving techniques are used in manufacturing industries to reduce rejection rate caused in production line and to improve quality of a product. This study mainly focuses on shainin methodology integrated with six sigma DMAIC, in which various steps were followed to detect and validate the root cause for causing excess vibration of control rod in A-type fuel injection pump.
\end{abstract}

\section{Introduction}

"A-type" fuel injection pump is a 6-cylinder FIP which is commonly used in heavy load carrying vehicles. It consists of 6 elements (Plunger and barrel) which pumps fuel to 6 engine cylinders [4], but all 6 elements are controlled by same control rod which controls delivery rate of each element. The construction of A-type FIP is shown in figure 1. This upward and downward motion of plunger in the element is caused by cam shaft which is attached to engine output through coupling. Other side of the shaft is attached to governor which is connected to control rod by a link present in governor cover. Vibration causes damages to parts of FIP which reduces its life.

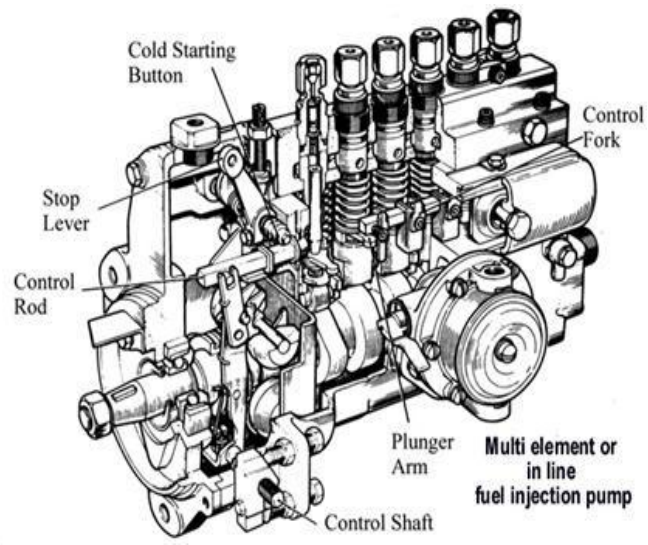

Fig. 1: Multi-cylinder fuel injection pump

In comparison with Taguchi methods, Shainin techniques are much simpler, less costly and statistically more powerful [3]. Shainin is integrated with six-sigma DMAIC for this project. In this project we have not considered Improvement and control stages of the six-sigma. Once the root cause was found for the control rod vibration issue, necessary changes were reported.

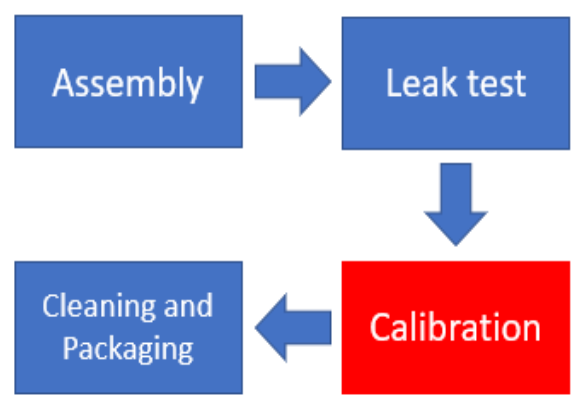

Fig. 2: Manufacturing process

After assembly process, pump passes through leakage test and then to calibration bench, where delivery of pump at different rpm, stability of control rod, control rod movement w.r.t the delivery, etc. is checked and then it passes through cleaning and packaging. The rejection due to control rod vibration is observed at calibration bench

\section{Shainin Approach}

As this product is high in demand, it is manufactured in high number and intervention into the process is difficult as it affects the production rate. Shainin is the best suited problem-solving technique in such cases [5].

\section{Define}

The rejections due to control rod vibration is $2^{\text {nd }}$ highest thus resulting in production loss. The main aim of this project is to detect the root cause of the problem causing excess vibration of control rod and to provide a solution to prevent it. 


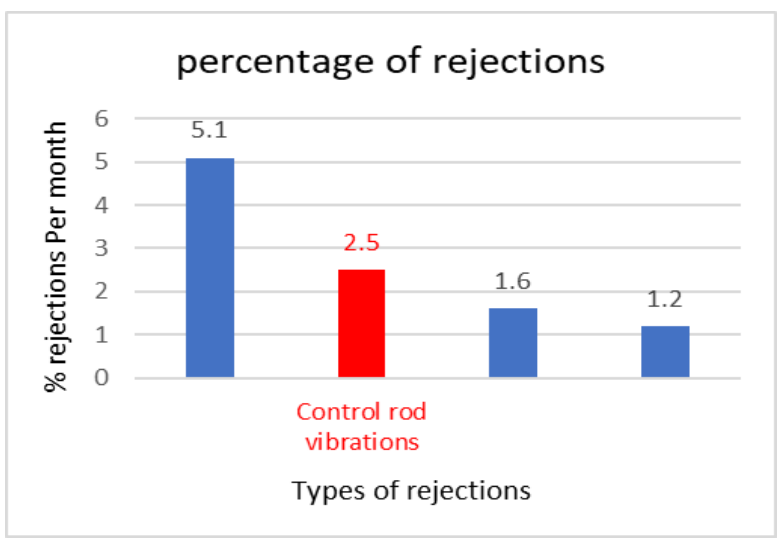

Fig. 3: Percentage of rejections per month

Problem definition is named as Green $\mathrm{Y}$ in shainin methodology and Red X is the root cause for Green Y [1]. Therefore, Green Y for current project is as follows

Green Y: Control rod vibration of diesel fuel injection pump.

\section{Measure}

30 pumps were calibrated on the calibration bench twice and isoplot was generated which will help in checking the variation in measurement through discrimination ratio [2]. Isoplot generated by the experimental data is shown in figure 4 . As the discrimination ratio is 10.75 (more than 6.0), accuracy of the calibration bench is good. Hence, we can negate any variation in measurement.

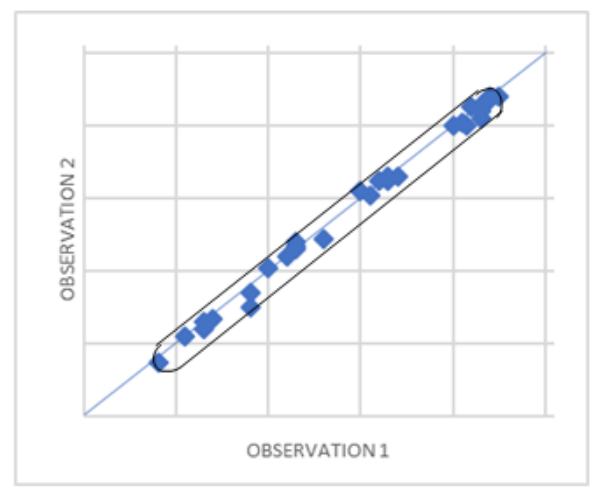

Fig. 4: Isoplot

The only left out option is variation in process which is contributing to cause a defect.

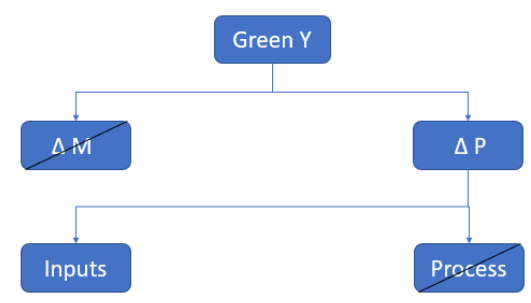

Fig. 5: Project definition tree

Now, to check the flaws in the process, 10 samples were tested and calibrated on 9 calibration benches available. No considerable evidence was found which can prove the process to be a major factor causing Green Y. therefore we can negate the presence of flaw in process. It is clear from the problem definition tree that, root cause lies in a component present in fuel injection pump.

\section{Analysis}

To find the Red X component, 3 pumps were selected through component search with which further experimentation can be carried out.

1) Component search: In this stage, we collect bad pumps, dismantle and reassemble (D\&R) twice and calibrated twice. Those pumps are selected which shows minimum variation in their control rod vibration values as shown in figure.

After this, three good pumps were collected and paired with these three bad pumps such that they have highest difference in their values.

By these values, decision limits are achieved for each bad pump and good pump.

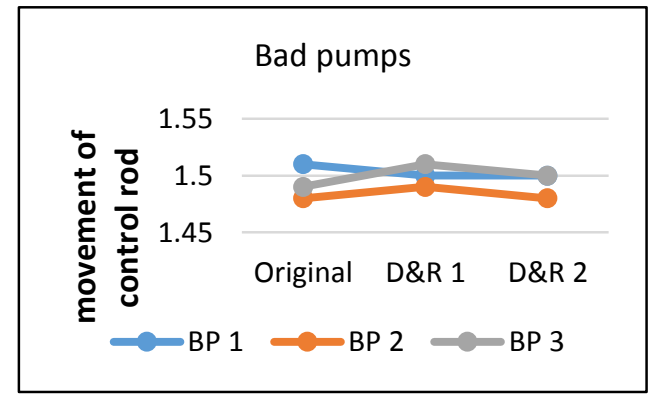

Fig. 6: Selection of bad pumps

Decision limits $(D L)=$ mean \pm constant $* d$

Where,

$\mathrm{d}=($ sum of standard deviation for good and bad pump $) / 2$

Constant $=1.31($ group size of 3$)$

$\mathrm{DL}_{\mathrm{GP}}=$ Decision limits of good pump

$\mathrm{DL}_{\mathrm{BP}}=$ Decision limits of bad pump

2) Components Swap: After pairing, suspected components in pump are identified which are as follows

1. Governor

2. Governor cover

3. Bearing flange

4. Cam shaft

These suspected components are swapped individually between good and bad pumps in each pair until good turns bad and bad turns good pump. Component swapping for one pair is shown in figure 7 .

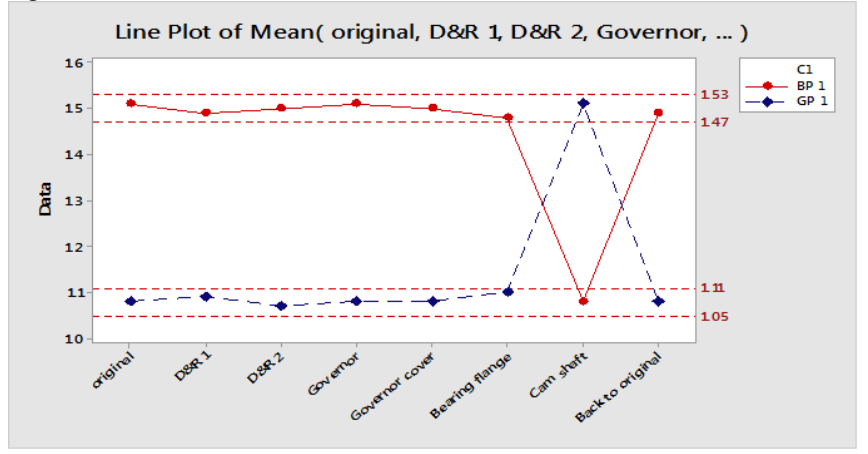

Fig. 7: Components swap results

It is clear from figure 7 that on swapping cam shaft between good and bad pump, bad pump turns to be good and good pump turns bad and same results were observed on swapping cam shaft for other two pairs which indicates the presence of Red $\mathrm{X}$ in cam shaft.

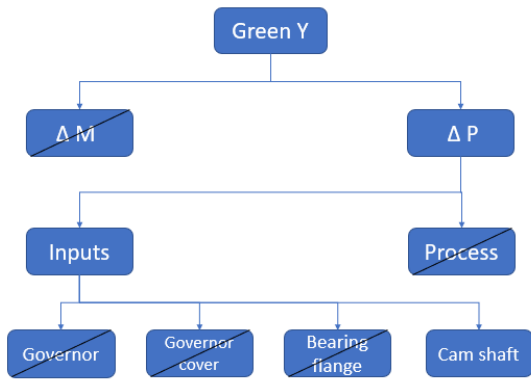

Fig. 8: Project definition tree with cam shaft as Red X component 
On further analysis on cam shaft between good pump and bad pumps, it is found that the overall length of cam shaft is less than length of pump casing for all three bad pumps. The interference between cam shaft assembly and pump casing for good and bad pumps is shown in table

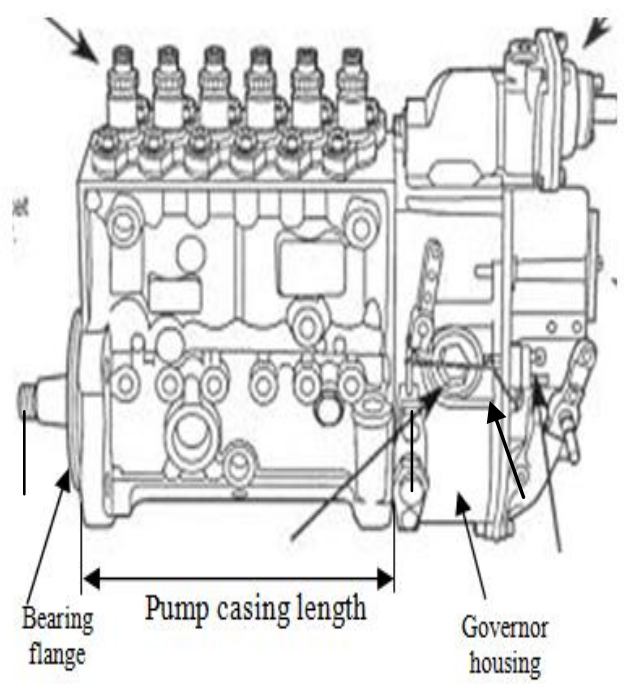

Fig. 9: Six-cylinder FIP with dimensions

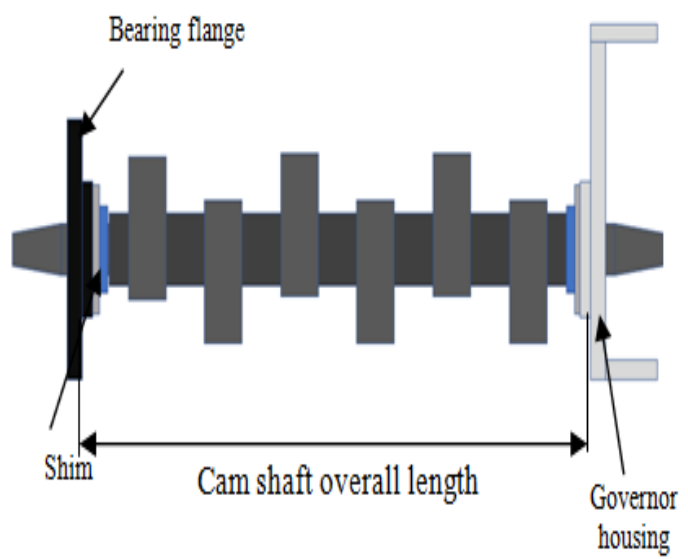

Fig. 10: Cam shaft assembly

Ideal condition:

(Pump casing length $<$ (overall cam shaft length $)$

Interference $=($ Overall cam shaft length $)-($ Pump casing length $)$ .........mm

Overall cam shaft length $=A+B+C+D \ldots \ldots . m m$

Where,

Cam shaft length (Collar to collar) (A)

Governor housing bearing height (B)

Shim thickness $(\mathrm{C})=$ Left side shim + Right side shim

Bearing flange height (D)

Table I: Interference Results

\begin{tabular}{|c|c|}
\hline Pumps & \multicolumn{2}{|c|}{ Interference } \\
\hline BP 1 & -0.12 \\
\hline BP 2 & -0.09 \\
\hline BP 3 & -0.17 \\
\hline GP 1 & 0.55 \\
\hline GP 2 & 0.37 \\
\hline GP 3 & 0.37 \\
\hline
\end{tabular}

It is observed that interference in bad pump is negative which means overall length of cam shaft is less than pump casing length whereas good pumps follows ideal condition. The reason for this negative interference in bad pumps is further analyzed by finding contrast in various dimensions between good and bad pumps
Table II: Comparison of Component Dimensions
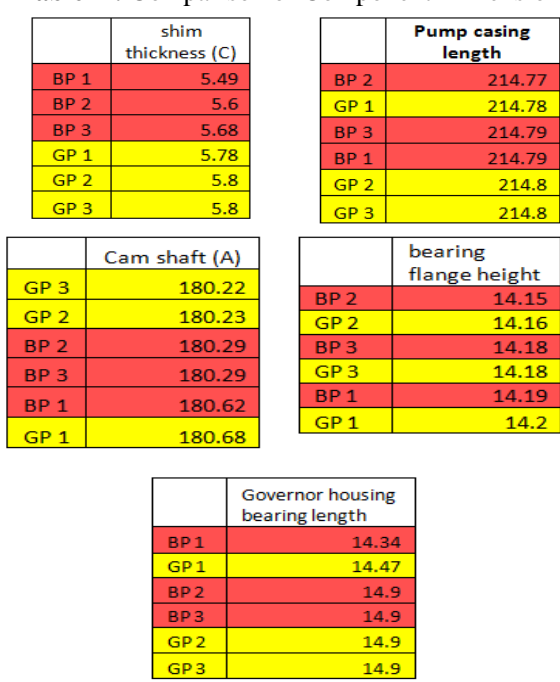

It is clear from above table that, left side shim thickness is less for all three bad pumps and more for good pumps. Therefore, left side shim thickness shows maximum contrast when compared between good and bad pumps.

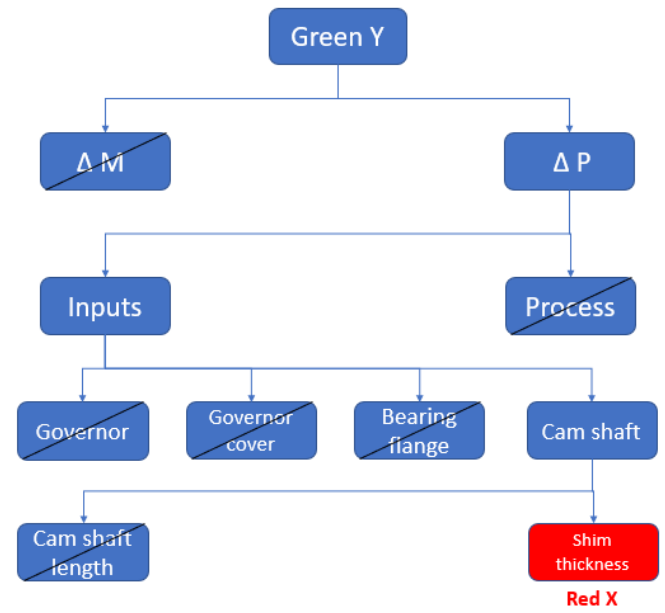

Fig. 11: Project definition tree with shim thickness as Red $X$ factor

The shim thickness of all three bad pumps were replaced with required thickness of shim and re-calibrated which is shown in table below.

Table III: Evaluation Results with Improved Shim Thickness

\begin{tabular}{|c|r|r|r|r|}
\hline pumps & $\begin{array}{c}\text { original shim } \\
\text { thickness }\end{array}$ & $\begin{array}{c}\text { Vibration with } \\
\text { original shim }\end{array}$ & $\begin{array}{c}\text { New shim } \\
\text { thickness }\end{array}$ & $\begin{array}{c}\text { Vibration with } \\
\text { new shim }\end{array}$ \\
\hline BP 1 & 5.66 & 1.51 & 5.96 & 1.14 \\
\hline BP 2 & 5.49 & 1.49 & 5.99 & 1.13 \\
\hline BP 3 & 5.6 & 1.49 & 5.9 & 1.17 \\
\hline
\end{tabular}

During assembly process shims are taken from rack arranged nearby. These boxes are labeled as per shim thickness which helps the operator to identify the correct shim. During this process an operator looks at screen on interference bench and then manually selects the shim of required thickness. Therefore, Red X can be defined as follows:

Red X: left side Shim thickness selection process.

\section{Conclusion}

Experimental investigation of excess control rod vibration by shainin methodology revealed that the process of shim thickness selection process is the root cause (Red X). The thickness of shim selected is not enough to cause a positive interference which causes some translational movement of cam shaft in pump case during rotation. The frequency of translational movement increases at full load which is transmitted to control rod and causes it to vibrate more than specified value. Further in this 
study, the error in shim thickness selection process can be eliminated by automation techniques.

\section{Acknowledgment}

I take this opportunity to express my profound gratitude and deep regards to Dr. D. Shrikant Rao, Dr. Gopalakrishna Prabhu and Dr. Jagannath Korody for their exemplary guidance, monitoring and constant encouragement throughout the course of this thesis. The blessing, help and guidance given by them time to time shall carry me a long way in the journey of life on which I am about to embark.

I also take this opportunity to express a deep sense of gratitude to Mr. Raghuveer Prasad, Deputy Manager, Bosch ltd., for his cordial support, valuable information and guidance, which helped me in completing this task through various stages.

\section{References}

[1] Veeresha G, Vijay KS, Chandan KS, Chetan KP \& Shashank RJ, "Reduction of idle-hunting in diesel fuel injection pump", International research journal of engineering and technology, Vol.4, (2017), pp.1354-1360.

[2] Bewoor AK \& Pawar MS, "Use of shainin tools for simplifying six sigma implementation in QMS/ISO certified environment-an Indian SME case study", Journal of engineering research studies, Vol.1, (2010), pp.177-194.

[3] Steiner SH, MacKay RJ \& Ramberg JS, "An overview of the shainin system for quality improvement", Quality engineering, Vol. 20, (207), pp.6-19.

[4] Sanket SK, Virupakshappa NM \& Achutha UK, "Root cause analysis of rough conical seat grinding problem in fuel pump cylinder head by shainin methodology", Proc. MATEC Web of Conferences, (2018).

[5] Anupama P, "Using shainin DOE for Six Sigma: an Indian case study", Production Planning and Control, Vol.27, (2015), pp.83101. 